\title{
Construções subordinadas com o verbo saber em uma perspectiva cognitivo-funcional
}

DOI: http://dx.doi.org/10.21165/el.v49i2.2645

\section{Flavia do Carmo Bertasso'}

\section{Resumo}

O objetivo deste trabalho é investigar o funcionamento de diferentes construções com o verbo saber, sob o aparato teórico da Linguística Cognitiva, especialmente Langacker (1987, 1991, 2009). A partir de dados do português falado no interior paulista, busca-se descrever os usos do verbo saber em contextos de complementação oracional com o propósito de determinar quais são suas formas e funções na variedade do português investigada. Os resultados mostram que o verbo saber: (i) no uso com função textualinterativa, é encontrado mais vezes na terceira pessoa do singular, no presente do indicativo e em posição final na oração, e (ii) no uso como matriz de oração completiva, o verbo é mais utilizado na primeira pessoa do singular, no presente do indicativo e em posição inicial na oração.

Palavras-chave: subordinação; oração completiva; português falado; linguística cognitiva.

1 Universidade Estadual Paulista "Júlio de Mesquita Filho" (UNESP), São José do Rio Preto, São Paulo, Brasil; flavia_bertasso@hotmail.com; https://orcid.org/0000-0003-1105-5763 


\title{
Subordinate constructions with the verb saber in a cognitive- functional approach
}

\begin{abstract}
The aim of this research is to investigate how different constructions with the verb "saber" (to know) are used in Portuguese, in accordance with the Cognitive Linguistics theoretical approach, especially Langacker $(1987,1991,2009)$. Based on the data from IBORUNA, with Portuguese spoken in the interior of São Paulo, the research intends to describe the uses of the verb "saber" in contexts of clausal complementation, with the purpose of determining the forms and functions of these constructions in the Portuguese variety investigated. The results show that the verb "saber": (i) in the performative use is mostly found in the third person singular, in the present in indicative mood and in final position in the sentence, and (ii) in the descriptive use, it is mostly used in the first person singular, in the present in indicative mood and in initial position.
\end{abstract}

Keywords: subordination; complement clauses; spoken Portuguese; cognitive linguistics.

\section{Introdução}

No âmbito dos estudos sobre a gramática do português brasileiro, várias pesquisas já foram desenvolvidas com o propósito de descrever aspectos da subordinação de orações, particularmente sob o paradigma teórico do funcionalismo linguístico. Como exemplo de tais estudos, e analisando as orações completivas, pode-se citar os de Braga (1999a, b) sobre orações encaixadas e complementos oracionais em português brasileiro e português do Alto Xingu, os de Neves $(2000,2002)$, sobre diferentes usos das orações completivas e dos aspectos gramaticais envolvidos nessas construções do português, os de Cezário (2001), acerca de níveis de integração oracional com verbos cognitivos e volitivos, de Carvalho (2004), que trata de orações encaixadas em verbos cognitivos e causativos, de Sousa $(2007,2010,2012,2013,2015)$ sobre gramaticalização de orações completivas em perspectiva diacrônica, de Gonçalves, Sousa e Casseb-Galvão (2008) e de Sousa et al. (2016), que tratam especificamente de descrever o funcionamento das tradicionalmente denominadas "subordinadas substantivas" no português falado. No tocante às orações adverbiais, encontram-se os trabalhos de Neves (2000, 1999a, b, c), relacionados a orações condicionais, causais e concessivas, de Braga (1999c) com construções de tempo no português falado no Brasil, de Decat (1999) a respeito dos modos de estruturação da hipotaxe adverbial, de Neves, Braga e Dall'Aglio-Hattnher (2008), também sobre as orações subordinadas adverbiais no português falado. Em relação às orações adjetivas, por fim, destacam-se os estudos de Decat $(2005,2014)$, acerca de orações relativas apositivas, de Bispo (2014), que descreve estratégias de relativização no português brasileiro e de Oliveira e Amorim (2014), a respeito do comportamento das subordinadas adjetivas do português sob uma abordagem funcionalista. 
A respeito do verbo saber, que interessa mais diretamente a essa pesquisa, Gonçalves, Sousa e Casseb-Galvão (2008, p. 10), ao investigarem as construções completivas e o tipo semântico dos verbos encaixadores de complemento oracional, classificam-no como verbo de cognição, que funciona, no português falado, como um verbo que demonstra "conhecimento por parte do referente do sujeito da sentença principal". Já Neves (2000), em sua Gramática de usos do Português, apresenta uma classificação semântica para saber como verbo "factivo epistêmico", uma vez que, quando complementado por oração, tal verbo supõe que a pressuposição completiva seja factual do ponto de vista do falante.

Embora esses estudos também abordem aspectos cognitivos ao verificarem a estrutura das construções subordinadas, tais aspectos não são tratados como foco central da pesquisa, além de não serem relacionados ao próprio conceito de subordinação.

Com este artigo, pretende-se realizar uma análise da complementação oracional sob uma perspectiva cognitivo-funcional com foco em fatores cognitivos e discursivos presentes nas construções completivas. Assim, para este estudo, foi adotado o conceito cognitivo de subordinação de orações proposto por Langacker (2009), segundo o qual a subordinação equivale a uma relação entre processos perfilados que se combinam de diferentes modos em "janelas de atenção conceitual" (LANGACKER, 2009). Em termos discursivos, entende-se, nessa proposta, que a subordinação equivale a uma relação entre espaços mentais (FAUCONNIER, 1985) destinados a fornecer instruções ao interlocutor acerca do domínio sob o qual uma proposição deve ser compreendida (VERHAGEN, 2005; LANGACKER, 2009).

Langacker define as janelas de atenção como "unidades de informação", no sentido de Chafe (1994). Segundo a teoria cognitiva de Langacker, uma unidade de informação corresponde esquematicamente a um pareamento simbólico entre uma janela de atenção conceitual e um grupo fonológico de entonação. Para o autor, a combinação de orações pode ser vista a partir daí como combinações variáveis de unidades de informação, em diferentes graus de perfilamento (primário/secundário) entre estados-de-coisas e proposições.

Para ilustrar essa concepção, são apresentados, a seguir, exemplos de construções completivas. Em (01), encontram-se construções extraídas de Langacker (2009) e em (02) a (05), ocorrências do português falado que integram o banco de dados IBORUNA, utilizado neste trabalho:

(01) a) Bush has conclusively demonstrated that evolution is only conjecture.

Bush afinal demonstrou que a evolução é apenas uma conjectura.

b) Is evolution only conjecture? Well, the president has definitely decided that it is.

A evolução é apenas uma conjectura? Bem, o presidente definitivamente decidiu que é. 
c) Evolution is only conjecture, I think.

A evolução é apenas uma conjectura, eu acho.

(02) Inf:: olha meu pai ele conta assim:: bastante coisa assim:: ele é mu::ito bom pra isso... eu pergunto várias coisas pra e:.le uma vez... eu tenho um problema de cólica também cólica eu num/ eu tenho mal absorção à lactose... e às vezes ele:: tinha que::/ ainda num sabia que era isso né? e eu tinha có:.lica gases e... de noite ele tinha que saí(r) pra dá(r) uma vo:.Ita comigo... porque eu passava mal... (IBORUNA - AC-006, L140)(03).

(03) Inf.: por QUÊ?.... porque ela achô(u) que a gente fosse conseguí(r)... avançá(r)... RÁpido... e eu não sei porquê mas... EU... éh:.... me detive aos detalhes... e todo e qualqué(r) probleminha eu enrosquei e num andei... e ela sabe que esse não é bem o meu perfil então eu sô(u) uma pessoa mais... né? -"vamos vê(r) vamo(s) (inint.)" - ... e eu não qué(r) dizê(r) eu mudei também... (IBORUNA -AI-001, L11).

(04) Doc.: POR que que cê acha que tem que sê(r) estudioso? Inf.: eu Acho que tem que sê(r) estudioso pra [...] pra você::.... éh:: tirá(r) notas bo::as sabe?...PRA você APRENDÊ(R) (IBORUNA - AC-002, L128).

(05) cê nem nem conhecia a:: o rosto dele como que ele tava... e o (filho) meu filho F. tava tam(b)ém em o(u)tro quarto em observação... porque ele:: ele saiu pelo vidro e ele cortô(u) assim o ombro né? ele vazô(u) pelo vidro que era pequenininho também né?... sei que foi uma coisa muito muito chata né?... de:: desse acidente (IBORUNA -AC 136, L68).

Conforme descrição de Langacker, (01a) possui uma estrutura composta, com dois estados-de-coisas concebidos de modo integrado, assim como as ocorrências (02) e (03), em que saber possui um uso descritivo, pois descreve a posse de um conhecimento por parte do sujeito da oração. Os estados-de-coisas presentes nessas ocorrências são conceitualmente percebidos como integrados e comprimidos em uma única janela de atenção, a qual contém as informações mais relevantes e sobre a qual recai o foco de atenção durante a fala. Em (01b), por outro lado, cada oração mantém sua própria janela de atenção, e a construção pode ou não ser concebida como uma estrutura composta, a depender de se os processos perfilados são ou não concebidos como integrados. Em (01c) e nas ocorrências (04) e (05), por fim, tem-se necessariamente uma concepção integrada de estado-de-coisas, mas não há dois relacionamentos perfilados como em (01a); o que ocorre em (01c) é que um relacionamento não perfilado (acho) serve para qualificar epistemicamente um processo perfilado (A evolução é apenas uma conjectura).

$\mathrm{Na}$ ocorrência em (04), saber serve ao monitoramento da interação por parte do falante, atuando como um marcador discursivo destinado a atestar a compreensão do interlocutor sobre o que é dito. Já em (05), o verbo parece atuar na organização discursiva, marcando o ato de fala que introduz (foi uma coisa muito, muito chata a desse acidente) como o encerramento, com uma avaliação final, do tópico discursivo que vinha sendo desenvolvido (o acidente). 
Nesses dois usos, pode-se afırmar que saber assume funções mais pragmáticodiscursivas, cujo uso baseia-se na interação, ou seja, representam instância de usos a que Diessel e Tomasello (2001) denominam "performativos", em oposição aos usos descritivos de verbos encaixadores de oração principal, tais como os que aparecem em (1c), (2) e (3). Há, nesses usos performativos de saber, combinação menos integrada de estado-de-coisas, uma estrutura na qual apenas um processo é perfilado, aquele que aparece na parte que equivaleria à oração encaixada, sendo subsidiário o significado do verbo saber.

Quanto à definição mais apropriada de subordinação em relação às construções completivas, foco deste artigo, Langacker (2009, p. 339, tradução nossa) propõe que: "Podemos então buscar definir as noções de principal e oração subordinada em termos discursivos: uma oração principal é aquela cujo perfil é mantido como tal, e uma oração subordinada, aquela cujo perfil é sobrepujado, em uma janela de atenção."2.

Conforme se pode notar a partir das ocorrências apontadas, a cada um dos diferentes usos de saber, com função descritiva ou pragmática, correlacionam-se propriedades gramaticais específicas, as quais se pretende identificar neste trabalho. Um segundo objetivo com este artigo é averiguar se os modos de subordinação completiva proposto por Langacker (2009), a partir de exemplos construídos do inglês (1a-c), podem ser aplicados inteiramente aos dados empíricos, extraídos de banco de dados composto por registros reais de fala.

\section{Material e método}

Considerando-se os propósitos deste artigo, o universo de investigação foi constituído por dados reais de uso da língua. Assim, elegeu-se como corpus da pesquisa as amostras de fala que integram o banco de dados IBORUNA, sediado na UNESP de São José do Rio Preto, o qual é composto por amostras de fala divididas em dois tipos: Amostra Censo e Amostra de Interação Dialógica. A Amostra Censo é formada por 152 amostras de fala controladas sociolinguisticamente, cada uma dividida em cinco tipos de texto: narrativa de experiência, narrativa recontada, descrição de local, relato de procedimento e relato de opinião. A Amostra de Interação, por sua vez, constitui-se de registros de fala coletados, de forma secreta, em situações livres de interação entre dois ou mais informantes. O banco de dados IBORUNA foi escolhido como fonte de dados para este trabalho primeiramente porque não há, até o momento, estudos sobre construções subordinadas com o verbo saber em perspectiva cognitivo-funcional que se voltem a esta variedade do português; em segundo lugar, porque o objetivo deste estudo é justamente analisar usos

2 No original: "We could then go on to define the notions "main" and "subordinate clause" in discourse terms: a main clause is one whose profile is maintained as such, and a subordinate clause one whose profile is overridden, in a window of attention". 
do verbo saber por falantes no momento da interação, focalizando, portanto, dados reais de interação verbal.

Também em razão dos objetivos projetados para esta pesquisa, foram investigados os inquéritos que compõem a Amostra de Interação do banco de dados IBORUNA, uma vez que eles favoreceram a ocorrência das construções em análise, em comparação aos inquéritos da Amostra Censo. Ao todo, foram analisados 106 dados de construções com saber.

Para a análise dos dados e sistematização dos resultados, foi utilizada metodologia de análise tanto qualitativa quanto quantitativa. Assim, os dados coletados foram, inicialmente, analisados de acordo com os seguintes fatores:

1) Tipo de uso do verbo saber: descritivo ou performativo (pragmático);

2) Tempo-modo apresentado pelo verbo saber: presente, passado ou futuro dos modos indicativo ou subjuntivo;

3) Pessoa gramatical indicada no verbo saber: $1^{a}, 2^{a}$ ou $3^{a}$ pessoa do singular ou do plural;

4) Posição da construção com saber em relação à proposição com que ela se combina: inicial ou final.

Após análise e codificação das ocorrências segundo a atuação desses fatores, os dados foram submetidos ao programa estatístico Goldvarb (SANKOFF; SMITH; TAGLIAMONTE, 2005), a fim de se obter resultados percentuais de aplicação dos fatores e, com isso, definir as propriedades típicas de cada uso identificado das construções em análise ${ }^{3}$.

\section{Resultados e discussão}

Após submeter ao programa Goldvarb os dados dos usos do verbo saber de acordo com sua função - textual-interativa ou descritiva - para analisar a combinação de orações com saber segundo a teoria cognitiva de Langacker (2009), foi possível determinar propriedades típicas de cada uso acerca da posição da construção na sentença, pessoa, tempo e modo verbais e observar como os fatores selecionados para a análise aparecem

3 Neste trabalho, o programa Goldvarb, diferentemente de sua aplicação nos estudos sociolinguísticos, é empregado somente como uma ferramenta estatística que permite submeter dados a um mesmo conjunto de fatores para a obtenção de frequência de aplicação e, com isso, de tendências comportamentais das formas em análise. 
nas construções estudadas. Buscou-se reconhecer as propriedades de saber a fim de relacioná-las aos modos de integração da combinação de orações estabelecidos por Langacker (2009).

A tabela a seguir mostra os resultados para a pessoa gramatical.

Tabela 1. Resultados para a pessoa gramatical do verbo saber

\begin{tabular}{|c|c|c|c|c|}
\hline Pessoa & $\begin{array}{l}\mathbf{N} \\
\%\end{array}$ & $\begin{array}{l}\text { Função textual- } \\
\text { interativa }\end{array}$ & $\begin{array}{c}\text { Função de matriz de oração } \\
\text { completiva }\end{array}$ & Total \\
\hline $1^{\text {a }}$ pessoa do singular & $\begin{array}{l}N \\
\%\end{array}$ & $\begin{array}{c}3 \\
7,5 \\
\end{array}$ & $\begin{array}{c}38 \\
57,5 \\
\end{array}$ & $\begin{array}{c}41 \\
38,7 \\
\end{array}$ \\
\hline $3^{a}$ pessoa do singular & $\begin{array}{l}N \\
\%\end{array}$ & $\begin{array}{c}37 \\
92,5\end{array}$ & $\begin{array}{c}27 \\
40,9\end{array}$ & $\begin{array}{c}64 \\
60,4\end{array}$ \\
\hline $3^{\mathrm{a}}$ pessoa plural & $\begin{array}{l}N \\
\%\end{array}$ & - & $\begin{array}{c}1 \\
1,5\end{array}$ & $\begin{array}{c}1 \\
0,9 \\
\end{array}$ \\
\hline Total & $\begin{array}{l}\mathrm{N} \\
\%\end{array}$ & $\begin{array}{c}40 \\
100\end{array}$ & $\begin{array}{c}66 \\
100\end{array}$ & 106 \\
\hline
\end{tabular}

Fonte: Elaboração própria

Observa-se que, com função textual-interativa, a construção equivale a uma combinação menos integrada de estado-de-coisas na qual apenas o processo referente à oração encaixada é perfilado. Nesse tipo de construção, saber aparece em 3 ocorrências (7,5\%) na primeira pessoa do singular (sei), indicando retomada ou fechamento de um tópico discursivo. São casos como o de (6):

(06) Inf.3.: (num é assim se se) cê tem aquela portaria de trás mais perto do lá de trás (inint.) ou é aquela porta[ria] que é mais longe?

Inf.1.:[não]... é assim tem o:.... ((barulho de digitação)) éh:: não é a portaria do I.C.M.C.é a portaria do OUtro lado... só que como... a lar/ ele não é tão largo... [Inf.3.(inint)?] não... te $\mathrm{dev} /$ por onde entra... EN/ eu sei que você entra ali cê passa DO LADO...da engenharia... cê passa a engenharia fica atrás do I.C.M.C.atrá/ éh:: mais ou210menos atrás do I.C.M.C.tem uma praça... num sei se cê foi nessa... se você foi nessa praça (IBORUNA - Al008, L208).

Na terceira pessoa do singular, como marcador discursivo (sabe?), saber encontra-se em 37 ocorrências (92,5\%). Como ilustra o excerto em (07) abaixo, a construção, nesses casos, serve para que o falante se certifique da compreensão do interlocutor a respeito do que foi dito, monitorando, assim, a interação em andamento. Também nesses casos, observa-se o perfilamento da porção principal e o uso interacional de saber, como um espaço mental independente. 
(07) Inf.2.: é e coitado eles trabalhavam de noite... é de dia que eles ficam em casa [sabe? EnTÃO] uma no::ite por sema::na eles ti::nha pa ficá(r) em [casa... agora já] conseguiram transferí(r) pra durante o dia (IBORUNA - AI006, L116).

Utilizado como matriz de oração completiva com a função de descrever o conhecimento do sujeito, saber aparece sempre em construções com dois estados-de-coisas perfilados, comprimidos em uma única janela de atenção. Com essa estrutura, saber aparece nos dados em 38 ocorrências $(57,5 \%)$ na primeira pessoa do singular (sel), para indicar que o conhecimento descrito pertence ao sujeito falante. No caso das completivas com "sei + se", todas as ocorrências apareceram precedidas por negação (num/não sei se), indicando um desconhecimento do falante, que pode ser compreendido como uma dúvida sobre a veracidade do conteúdo contido na oração completiva, como em (08).

(08) Inf.1.: que horas vai passá(r) o Palme(i)ras amanhã? Inf.2.: num sei_que horas preciso vê(r) no jornal num sei se joga oito e meia Inf.1.: da NOlte? Inf.2: NUM SEI_preciso vê(r) jornal amanhã cedo falô(u) aí já esqueci (IBORUNA - AI007, L136).

Também com valor descritivo de um conhecimento, em construções mais integradas, saber aparece como matriz de completiva flexionado na terceira pessoa do singular (sabe) e, em apenas uma ocorrência, na terceira pessoa do plural. Como mostram as ocorrências a seguir, saber descreve, nesses casos, o conhecimento do sujeito da oração matriz.

Inf.1: a casa tá trancada? é isso?

Inf.2: ele tá lá dentro... ele bebe... ele sai bebe vai dormí(r)... e ele falô(u) pra mim quesó SAl se alguém for tirá(r) ele porque do contrário ele sabe que é da/ que é da menina... porque eu já enjoei de falá(r) que foi feito pra ela... mas ele disse que não sai (IBORUNA - Al009, L188)

(10) Inf.1: [é... não não não é pra sê(r) ouvido] mas pelo menos a hora que for fazê(r) esse boletim de ocorrência... tem que constá(r) o nome de uma ou duas testemunhas né? que... que sabem... da situação lá... que você tem fi::Iho... é deficiENte né? (IBORUNA - Al009, L62).

Na tabela a seguir, encontram-se os resultados para o fator tempo-modo verbal de saber na construção, conforme o seu funcionamento seja textual-interativo ou descritivo, como matriz de oração completiva em construções cujos estados-de-coisas são semântica e cognitivamente mais integrados. 
Tabela 2. Resultados para tempo-modo indicados no verbo saber

\begin{tabular}{c|c|c|c|c}
\hline Pessoas & $\begin{array}{c}\text { N } \\
\%\end{array}$ & $\begin{array}{c}\text { Função textual- } \\
\text { interativa }\end{array}$ & $\begin{array}{c}\text { Função de matriz de } \\
\text { oração completiva }\end{array}$ & Total \\
\hline $\begin{array}{c}\text { Presente no modo } \\
\text { indicativo }\end{array}$ & $\mathrm{N}$ & 39 & 58 & 97 \\
\hline Passado no modo & $\mathrm{N}$ & 97,5 & 87,8 & 91,5 \\
indicativo & $\%$ & 1 & 8 & 9 \\
Total & $\mathrm{N}$ & 4,5 & 12,1 & 8,5 \\
\hline & $\%$ & 100 & 66 & 106 \\
\hline
\end{tabular}

Fonte: Elaboração própria

No uso pragmático, em que o relacionamento se dá entre um estado-de-coisas perfilado e um qualificador interacional desse estado-de-coisas, saber aparece entre os dados em 39 ocorrências (97,5\%) no presente do modo indicativo, como em (11). A forma do presente nesses casos se explica pelo fato de a função exercida pela construção voltar-se para a interação verbal efetiva e em andamento.

(11) Inf.1.: E::LA senTA::va... ela por:./ punha:.... é.:... eu aQUI meu irmão aQUI... e ela sentava na o(u)tra carte(i)ra e ali óh..... ela ficava... explican(d)o...-"mas cês num sabe fazê(r) isso?" - nós falava assim -"não"-... e aí óh:: negócio de Aritmética que:: te::m de porcentagem NÓS NUM SABIA NADA DAQUI::Io de [porcenTA::GEM... de nada]

Inf.2:117é (porque na época era)] a Matemática ho:.je... de antigamente [Inf. 1: é] falava Aritmética

Doc.2.: é:: é

Inf.2.: é...[lingua::.gem o Português... era lingua::.gem]

Inf.1.:[então:: eu sei que ela senTA:.:va... EXPLICA.:VA EXPLICA::VA][Doc.2:é::] e eu sei que nós passô(u)... e eu e ele... tá [certo] (IBORUNA - AI004, L72)

No pretérito do indicativo, o verbo saber, usado pragmaticamente para o monitoramento da interação (sabia?), aparece em apenas uma ocorrência, mostrada em (12), o que revela ser essa forma verbal menos usual para esse marcador interacional. Uma observação interessante é que, nessa ocorrência, o marcador retoma um conteúdo também marcado no passado ("ai eu fiquei até com o dó do C."), referência temporal que pode influenciar a marca de pretérito também no marcador discursivo.

Inf.2: a::i vai dá(r) pa::u ((referindo-se ao computador))

Inf.1: por quê? fe/ fecha e abre de novo às vezes dá certo... ai eu fiquei até com dó do C. sabia? 
Inf.2: ai eu tô... com muita... pena dele assim... eu lembro do meu pai essas coisa sabe? M. operaçã::.... hospital:.... tensãa::o (IBORUNA - AI005, L63)

Utilizado como matriz de oração completiva, com dois estados-de-coisas perfilados e concebidos de modo integrado, saber aparece em 58 ocorrências $(87,8 \%)$ no presente do modo indicativo (seI), como em (13). A indicação, nesses casos, é a de que o sujeito da sentença tem um conhecimento sobre uma proposição - e também que a proposição é verdadeira de acordo com o falante - no tempo presente, no momento da interação verbal.

(13) Inf.: porque antes eu achava que eu não incomodá(r) ela era bom... só que eu tô ven(d)o que ela qué(r) é o seguinte que ela qué(r) que eu mostre pra ela que todo dia eu estudo sabe?... que eu num tô fazen(d)o tudo as pressa que eu num tô levan(d)o nas co::xa sabe assim?... eu falei eu vô(u) vê(r) se eu... agilizo a COlsa... eu sei que ela é difícil

mas... queren(d)o ou não hoje me caiu uma ficha estudando... eu sei porque que ela tá frustrada assim... eu entendi (IBORUNA - AI011, L5)

O verbo saber também é usado como descritor de um conhecimento no pretérito do indicativo (sabia), como em (14), em 8 ocorrências (12,1\%). Descreve-se, nesses casos, o conhecimento que o sujeito da oração detinha em momento anterior ao da interação. O conteúdo na oração completiva também é marcado como certo, verdadeiro para o falante.

Inf.1.: a:: foi pro E.... que o senhor falô(u) que vinha?

Doc.2.: fo::i:

Inf. 1.: ah::

Doc.2.: ele/ eu é/... é que eu sabia que ele era aqui de Onda Verde né?... que ele dá aula lá em Ilha Solte(i)ra... e eu... morei muitos anos em Ilha Solte(i)ra e um dia eu conheci ele (IBORUNA - AI004, L181)

Passa-se, a seguir, aos resultados da posição de saber em relação à proposição que ele modifica apenas em seus usos pragmáticos, ou textual-interativos, já que, em seus usos descritivos, saber aparece invariavelmente em posição inicial em relação à oração (completiva) com que ele se combina. 
Tabela 3. Resultados para a posição da construção com saber em relação à proposição com que ela se combina

\begin{tabular}{c|c|c|c}
\hline \multirow{2}{*}{ Pessoal } & $\mathbf{N}$ & Função textual-interativa & Total \\
& $\%$ & 3 & 3 \\
\multirow{2}{*}{ Inicial } & $\mathrm{N}$ & 7,5 & 7,5 \\
\hline \multirow{2}{*}{ Final } & $\%$ & 37 & 37 \\
& $\mathrm{~N}$ & 92,5 & 92,5 \\
\hline \multirow{2}{*}{ Total } & $\mathrm{N}$ & 40 & 40 \\
& $\%$ & 100 & 40 \\
\hline
\end{tabular}

Fonte: Elaboração própria

No uso pragmático, em que overbo se comporta como um modificador da sentença, saberé encontrado em 3 ocorrências (7,5\%) na posição inicial. Conforme ilustrado anteriormente, a construção serve nesses casos à retomada de um tópico provisoriamente abandonado, em geral pela inclusão de algum comentário ou subtópico, como em (15).

$$
\text { Inf.1.: EU GOSTAVA mas a minha professora nossa foi [baca::na (lá de Palesti::na)] }
$$

Inf.2.:[a:: mas professor aquela época era o(u)tra coi:.:sa né?]

Inf.1.: E:.:LA senTA.:va... ela por.:/ punha:.... é.:... eu aQUI meu irmão aQUI... e ela sentava na o(u)tra carte(i)ra e ali óh.:... ela ficava...explican(d)o... -"mas cês num sabe fazê(r) isso?"nós falava assim -"não" - ... e aí óh:: negócio de Aritmética que:: te::m de porcentagem NÓS NUM SABIA NADA DAQUI::Io de [porcenTA::GEM... denada]

Inf.2.: [é (porque na época era)] a Matemática ho:.je... de antigamente [Inf. 1: é] falava Aritmética

Doc.2.: é:: é

Inf.2.: é...[lingua:.:gem o Português... era lingua:.:gem]

Inf.1.: [então:: eu sei que ela senTA::va... EXPLICA::VA EXPLICA::VA] (IBORUNA Al004, L71)

A outra posição de saber pragmático é a final, representada no córpus por 37 ocorrências (92,5\%). Todas elas aparecem na forma "sabe?", como em (16), um marcador usado pelo falante para se certificar da atenção e compreensão do interlocutor a respeito do que é dito. 
(16) Inf.2: mas J... QUANdo o o o diretor do Hopi Hari foi seqüestrado porque ele tam(b) ém... o 0. que trabalhava junto... o ele e o 0. fazia tratamento c'uma psicóloga em São Paulo... o o:: M. salU... e entrô(u) na caminhonete... com aquelas caminhoneTOna sabe? (IBORUNA - AI001, L35)

\section{Conclusão}

A análise de construções subordinadas com saber empreendida neste trabalho, a partir de dados representativos do português falado, revela a existência de diferentes formas e funções das construções. Os modos de subordinação propostos por Langacker (2009), sob perspectiva cognitivo-funcional, com exceção do modo (b) que não foi investigado, mostram-se adequados para descrever essa diversidade de construções, o que demonstra a aplicabilidade da proposta, fundamentada em dados artificialmente construídos, a dados reais de interação verbal.

Em termos de propriedades gramaticais, os resultados mostram as seguintes tendências para os modos de integração em orações subordinadas estabelecidos por Langacker (2009):

(i) Quanto ao modo de concepção integrada com uma estrutura composta com dois estados-de-coisas em uma única janela de atenção, concebidos de modo integrado e atuando, sintaticamente, como matriz de oração completiva, saber é encontrado, na maioria dos casos, na primeira pessoa do singular e no presente do modo indicativo, sugerindo que, em construções com função descritiva, de descrição de conhecimento, o sujeito geralmente fala sobre um (des)conhecimento que pertence a ele no tempo presente. Acredita-se que essa característica se relacione ao tipo de corpus analisado (amostra de interação), o que carece ser mais bem investigado em pesquisas futuras. Ainda, o verbo com sentido descritivo ocupou somente a posição inicial em relação à proposição a qual se combina; na condição de matriz de uma oração completiva, o processo perfilado caracterizado pela oração principal mantevese anterior ao processo perfilado caracterizado pela proposição introduzida por saber na janela de atenção.

(ii) Quanto ao modo de concepção integrada, mas de combinações entre um estadode coisas perfilado e o outro não, saber ocorre com valor pragmático, com função textual-interativa. Na maioria dos casos, essa função se liga ao monitoramento da interação pelo falante, portanto, na terceira pessoa do singular e no presente do indicativo (sabe?), embora possa também servir ao falante para retomar ou concluir um tópico no momento da interação, empregado na primeira pessoa do singular e no presente do indicativo (eu sei que). Com respeito à posição da construção com saber em relação à proposição com a qual ele se combina, com função textual-interativa, há predomínio dessas construções na posição final com a finalidade de monitoramento 
da interação. Ressalte-se, por fim, que, conforme propõe Langacker (2009) em relação ao verbo think (achar) do inglês, nos casos de saber pragmático analisados neste trabalho, as construções performativas atuam como processos secundários em relação às construções que constituem processos perfilados, que ocupariam o lugar das orações encaixadas, mas que, muitas vezes, constituem um conjunto de proposições independentes, em vez de uma única oração subordinada, um aspecto não analisado por Langacker.

\section{REFERÊNCIAS}

BISPO, E. B. Estratégias de relativização no PB: motivações discursivo-interacionais e cognitivas. In: BISPO, E. B.; OLIVEIRA, M. R. (org.). Orações relativas no português brasileiro: diferentes perspectivas. Niterói: Editora da UFF, 2014. p. 131-156.

BRAGA, M. L. Os complementos oracionais no português do Brasil e no português de contato. Anais da Associação Brasileira de Lingüística, Florianópolis, 1999a. (CD-ROM da ABRALIN).

BRAGA, M. L. As orações encaixadas no dialeto carioca. Relatório Científico apresentado ao CNPQ, 1999b. Mimeo.

BRAGA, M. L. Os enunciados de tempo no português falado no Brasil. In: NEVES, M. H. M. (org.). Gramática do Português Falado. v. VII: Novos estudos. Campinas: FAPESP, 1999c. p. 443-461.

CARVALHO, C. Cláusulas encaixadas em verbos causativos e perceptivos: uma análise funcionalista. 2004. Tese (Doutorado em Linguística) - Instituto de Estudos da Linguagem, Universidade Estadual de Campinas, Campinas, 2004.

CEZÁRIO, M. M. Graus de integração de cláusulas com verbos cognitivos e volitivos. 2001. Tese (Doutorado em Linguística) - Universidade Federal do Rio de Janeiro, Rio de Janeiro, 2001.

CHAFE, W. L. Discourse, Consciousness, and Time: the flow and displacement of conscious experience in speaking and writing. Chicago/London: University of Chicago Press, 1994.

DECAT, M. B. N. Orações relativas apositivas desgarradas no português em uso. In: BISPO, E. B.; OLIVEIRA, M. R. (org.). Orações relativas no português brasileiro: diferentes perspectivas. Niterói: Editora da UFF, 2014. p. 157-190. 
DECAT, M. B. N. Orações relativas apositivas: SNs 'soltos 'como estratégia de focalização e argumentação. Veredas (UFJF), Juiz de Fora, v. 1 e 2, p. 83-103, 2005.

DECAT, M. B. N. Uma abordagem funcionalista da hipotaxe adverbial em português. In: NEVES, M. H. M. Descrição do Português: abordagens funcionalistas. Araraquara: UNESP/FCL, 1999. p. 299-318.

DIESSEL, H.; TOMASELLO, M. The acquisition of finite complement clauses in English: a corpus-based analysis. Cognitive Linguistics, v. 12, n. 1, p. 97-141, 2001.

FAUCONNIER, G. Mental Spaces. Cambridge, Mass.: The MIT Press, 1985.

GONÇALVES, S. C.; SOUSA, G. C.; CASSEB-GALVÃO, V. C. As construções subordinadas substantivas. In: NEVES, M. H. (org.). Gramática do Português culto falado no Brasil. Classes de palavras e processos de construção. Campinas: Editora da Unicamp, 2008. p. 1021-1088.

LANGACKER, R. W. Investigations in Cognitive Grammar. Berlin/New York: Mounton de Gruyter, 2009.

LANGACKER, R. W. Foundations of Cognitive Grammar. v. 2: Descriptive application. Stanford: Stanford University Press, 1991.

LANGACKER, R. W. Foundations of Cognitive Grammar. v. 1: Theoretical Prerequisites. Stanford: Stanford University Press, 1987.

NEVES, M. H. M. Construções encaixadas: considerações básicas. In: NEVES, M. H. M. A gramática: história, teoria e análise, ensino. São Paulo: Editora UNESP, 2002. p.151-162.

NEVES, M. H. M. Gramática de usos do português. São Paulo: EDUNESP, 2000.

NEVES, M. H. M. As construções condicionais. In: NEVES, M. H. M. (org.). Gramática do Português Falado. v. VII: Novos estudos. Campinas: FAPESP, 1999a. p. 497-544.

NEVES, M. H. M. As construções causais. In: NEVES, M. H. M. (org.). Gramática do Português Falado. v. VII: Novos estudos. Campinas: FAPESP, 1999b. p. 461-496.

NEVES, M. H. M. As construções concessivas. In: NEVES, M. H. M. (org.). Gramática do Português Falado. v. VII: Novos estudos. Campinas: FAPESP, 1999c. p. 545-596. 
NEVES, M. H. M.; BRAGA, M. L.; DALL'AGLIO-HATTNHER, M. M. As construções

hipotáticas. In: NEVES, M. H. (org.). Gramática do Português culto falado no Brasil. Classes de palavras e processos de construção. Campinas: Editora da Unicamp, 2008. p. 9371020.

OLIVEIRA, M. R.; AMORIM, M. B. Orações adjetivas na sala de aula em perspectiva funcionalista. In: BISPO, E. B.; OLIVEIRA, M. R. (org.). Orações relativas no português brasileiro: diferentes perspectivas. Niterói: Editora da UFF, 2014. p. 191-218.

SANKOFF, D.; TAGLIAMONTE, E.; SMITH, E. Goldvarb X: a variable rule application for Macintosh and Windows. Toronto: University of Toronto/Department of Linguistics, 2005

SOUSA, G. C. Motivações semânticas e pragmáticas na mudança gramatical. Caligrama: Revista de Estudos Românicos, v. 20, p. 53-72, 2015.

SOUSA, G. C. Percurso diacrônico de completivas introduzidas por "como" no português. Estudos Linguísticos, São Paulo, v. 42, n. 1, p. 366-375, 2013. Disponível em: https://revistas.gel.org.br/estudos-linguisticos/article/view/1112/678. Acesso em: 05 jun. 2020.

SOUSA, G. C. História de uma completiva: origem e desenvolvimento do complemento oracional introduzido por "se" do português. Alfa, Araraquara, v. 56, n. 1, p. 81-107, 2012.

SOUSA, G. C. Gramática e gramaticalização de construções completivas. In: NEVES, M. H. M. (org.). As interfaces da gramática (série Trilhas Linguísticas, n. 18). Araraquara: Cultura Acadêmica, 2010. p. 231-244.

SOUSA, G. C. Gramaticalização das construções com orações completivas: o caso do complemento oracional introduzido por se. 2007. Tese (Doutorado em Linguística e Língua Portuguesa) - Faculdade de Ciências e Letras, Universidade Estadual Paulista, Araraquara, 2007.

SOUSA, G. C. et al. As orações completivas subjetivas e objetivas. In: PEZATTI, E. G. (org.). Construções subordinadas na lusofonia: uma abordagem discursivo-funcional. São Paulo: Editora da Unesp, 2016.

VERHAGEN, A. Constructions of Intersubjectivity: Discourse, Syntax and Cognition. New York: Oxford University Press, 2005. 